\title{
Hepatitis B antigen (HBAg) and its antibody (HBAb) in hospital patients
}

\author{
R. W. PAYNE, A. BARR, AND J. WALLACE \\ From the Victoria Infirmary, Glasgow, and the Regional Transfusion Centre, Law Hospital, Carluke
}

SYNOPSIS Sera from 5171 inpatients have been tested for HBAg and HBAb during the 18-month period ending in December 1972. The incidence of $\mathrm{HBAg}(0 \cdot 116 \%)$ was similar to that in blood donors $(0.119 \%)$ in the same area, being tested for the first time by the same technique. By contrast the incidence of $\mathrm{HBAb}$ in patients $(0.271 \%)$ was significantly higher than in donors $(0 \cdot 103 \%)$. A possible mode of infection was identified in three of six HBAg-positive patients and in seven of 12 HBAb patients. None of the positive patients was regarded as 'high risk' when admitted to hospital. The study thus emphasizes the need to regard all specimens as potentially infective.

The hepatitis-associated antigen (HAA), formerly known as Australia antigen, appears to be a specific marker for 'serum' or viral hepatitis type B (Blumberg, Sutnick, and London, 1968; Prince, 1968). A recent World Health Organization report (1973) proposes that HAA or Australia antigen should be referred to as hepatitis $B$ antigen (HBAg) and the corresponding antibody as hepatitis $B$ antibody (HBAb). Although this antigen may not itself be the actual infective agent, any individuals found to be HBAg positive must be regarded as potentially infectious. There is little published information regarding the prevalence of HBAg in hospital patients, and indeed most of the available figures refer to prevalence rates in healthy blood donors. There is, however, no reason to suppose that patients referred to hospital are in this respect atypical and hospitals must constantly be treating unknown carriers of HBAg (Department of Health and Social Security, 1972a).

This study was primarily undertaken to determine the prevalence of HBAg and HBAb among selected inpatients in a general hospital group and among healthy blood donors in the same region over the same period of time; and secondarily to investigate implications of the findings.

\section{Materials and Methods}

\section{PATIENTS}

An aliquot of serum was obtained from each inpatient in whom blood grouping was performed in the Haematology Department of the Victoria Received for publication 9 November 1973.
Infirmary. The serum samples were stored at $-20^{\circ} \mathrm{C}$ and subsequently transferred at weekly intervals to the Glasgow and West of Scotland Regional Transfusion Centre for HBAg and HBAb testing. Sera from 5171 individual patients were tested between June 1971 and December 1972. These 5171 patients represented $29 \%$ of the patients admitted to hospital during the same period of time: $83 \%$ were admitted to surgical and $17 \%$ to medical wards.

A detailed medical history was obtained from those patients in whom HBAg or HBAb was detected; in addition biochemical tests of liver function were performed.

\section{BLOOD DONORS}

Since October 1970, the sera of all blood donors in the west of Scotland have been routinely tested for the presence of HBAg and HBAb; 86182 donors were tested for the first time between June 1971 and December 1972.

\section{LABORATORY METHODS}

All sera were tested for HBAg and HBAb by immunoelectroosmophoresis (IEOP). The screening procedure and confirmatory techniques have already been described (Wallace, Milne, and Barr, 1972). Repeat specimens for confirmatory tests were obtained from patients and donors found positive on preliminary testing.

\section{Results}

PREVALENCE OF HBAg

The sera of six out of a total of 5171 patients were 
HBAg positive $(0.116 \%)$, while 103 out of a total of 86182 blood donors were HBAg positive $(0 \cdot 119 \%)$ (table $\mathrm{I}$ ). The difference is not statistically significant.

\begin{tabular}{lll}
\hline & $\begin{array}{l}\text { Hospital } \\
\text { Inpatients }\end{array}$ & $\begin{array}{l}\text { Blood } \\
\text { Donors }\end{array}$ \\
\hline Number tested & 5171 & 86182 \\
HBAg positive & $6(0 \cdot 116 \%)$ & $103(0 \cdot 119 \%)$ \\
HBAb positive & $14(0.271 \%)$ & $89(0 \cdot 103 \%)$ \\
\hline
\end{tabular}

Table I $H B A g$ and $H B A b$ results in hospital inpatients and in blood donors

PREVALENCE OF HBAb

The sera of 14 out of a total of 5171 patients were HBAb positive $(0.271 \%)$, whereas 89 out of a total of 86182 blood donors were HBAb positive $(0.103 \%)$ (table I). This difference is statistically highly significant $\left(\chi^{2}=12 \cdot 149 ; \mathrm{P}<0.001\right)$.

\section{HBAg AND HBAb-POSITIVE PATIENTS}

\section{Diagnosis, age, and sex}

The principal diagnosis, age and sex of the six HBAg and of the $14 \mathrm{HBAb}$-positive patients are given in table II. It should be noted that none of these patients was icteric nor regarded as a 'high -risk' case in relation to transmission of hepatitis (Department of Health and Social Security, 1972b).

Possible modes of infection

The six HBAg patients and 12 of the $14 \mathrm{HBAb}$ patients were closely questioned concerning their previous medical history; in two HBAb patients this was not practicable. Particular attention was paid to a history of previous transfusion of blood or blood products; of jaundice occurring within six months of transfusion; of jaundice or hepatitis of unknown type or close contact with a jaundiced individual within the previous six months; of any injection within the previous six months and of previous pulmonary tuberculosis treated with chemotherapy. These findings are summarized in table III.

A history of blood transfusion before the screening of donations for $\mathrm{HBAg}$ was obtained from one of six HBAg patients and from six of $12 \mathrm{HBAb}$ patients; two of those HBAb patients had developed jaundice within six months of transfusion. None of the HBAg patients admitted to any episode of jaundice, but one admitted to close contact with a jaundiced individual during the previous six months. One of $\cong$ the HBAb patients admitted to an episode of jaundice some 30 years earlier, while, as noted above, two other patients had in the past had posttransfusion jaundice. Histories of injection within the previous six months were obtained from one HBAg patient and three $\mathrm{HBAb}$ patients. One $\mathrm{HBAg}$ patient and $\vec{\theta}$ three HBAb patients gave histories of pulmonarg $\perp$ tuberculosis treated with chemotherapy during the previous 10 years. Thus, in summary, a possiblè mode of infection was identified in three of si $\vec{x}^{+}$ $\mathrm{HBAg}$ patients and in seven of $12 \mathrm{HBAb}$ patients.

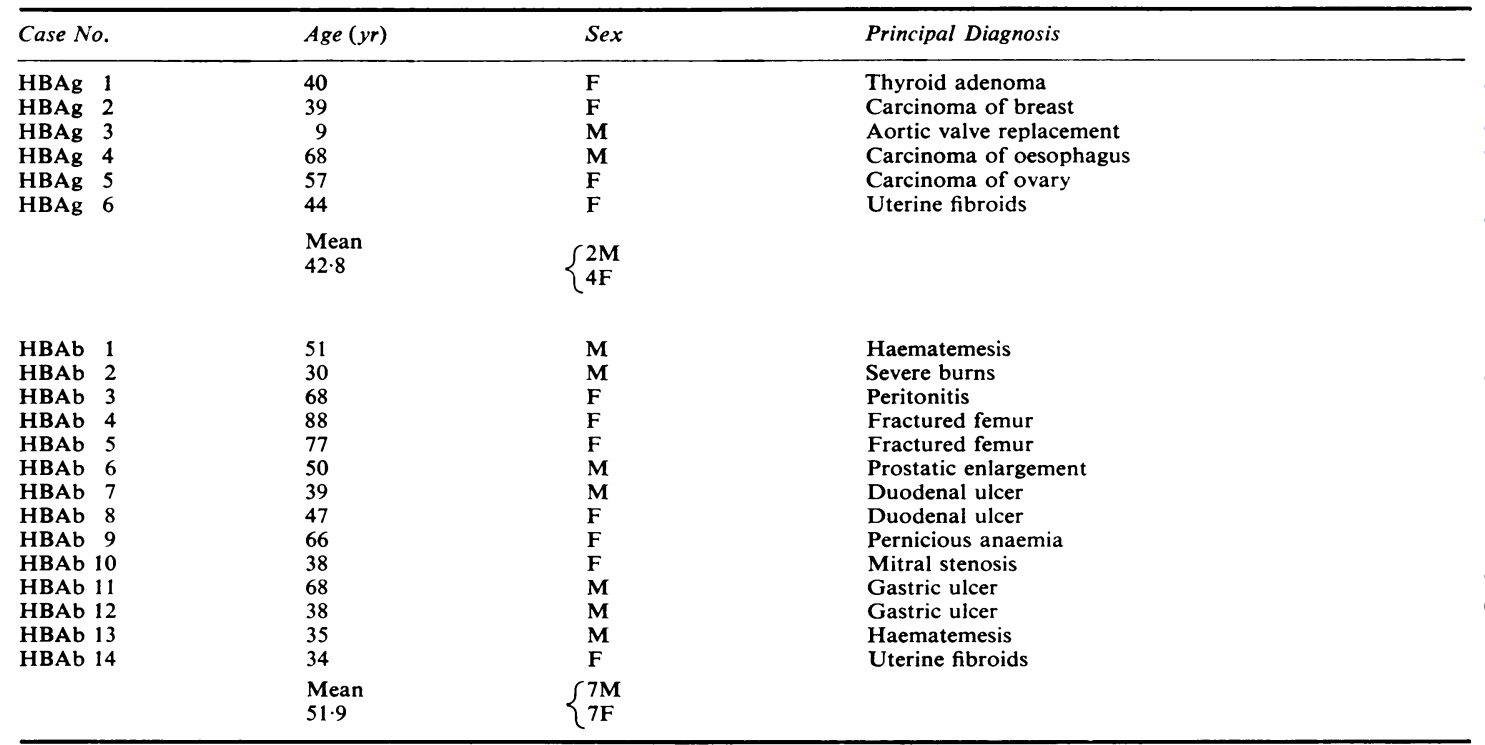

Table II Age, sex, and principal diagnosis of HBAg-and HBAb-positive hospital inpatients 


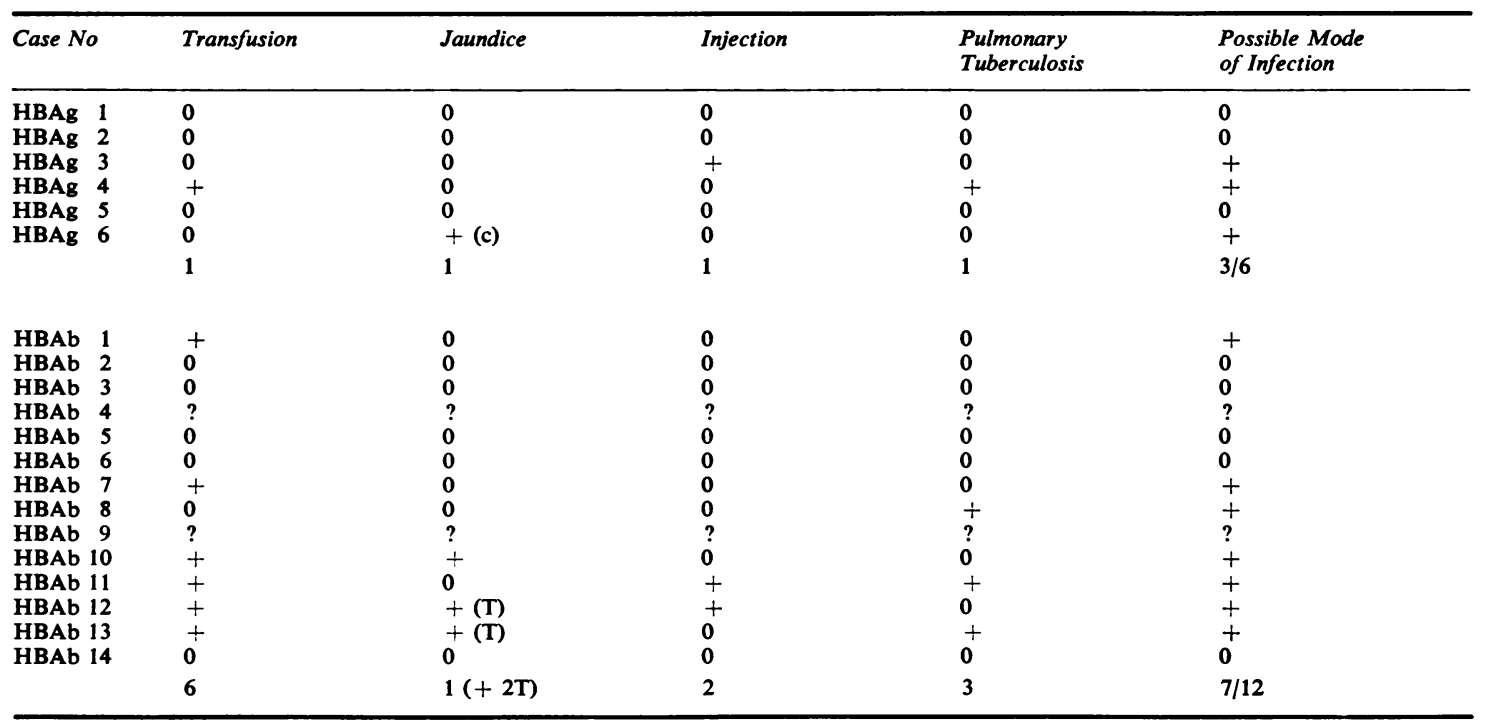

Table III Possible modes of infection in HBAg-and HBAb-positive hospital inpatients

+ History of exposure, + (c) contact with jaundice

0 No history of exposure, $+(T)$ posttransfusion jaundice

? No information available

\section{Liver function tests}

Conventional biochemical tests of liver function were performed in the six $\mathrm{HBAg}$ patients and in 12 HBAb patients; all results were within normal ranges.

\section{Laboratory specimens}

During the interval between the patients' admission and the availability of HBAg results, specimens were examined in a routine manner in various individual laboratories. The distribution of the specimens is given in table IV.

\begin{tabular}{lll}
\hline $\begin{array}{l}\text { Laboratory } \\
\text { Department }\end{array}$ & $\begin{array}{l}\text { No. of Patients } \\
\text { Investigated }\end{array}$ & $\begin{array}{l}\text { No. and Nature of } \\
\text { Specimens }\end{array}$ \\
\hline Clinical chemistry & 3 & 3 Blood \\
Haematology & 6 & 6 Blood \\
Histopathology & 5 & 2 'Unfixed' tissue \\
& & 3 Formalin-fixed \\
tissue \\
$\begin{array}{l}\text { Medical } \\
\text { microbiology }\end{array}$ & 2 & 1 Urine \\
\hline
\end{tabular}

Table IV Nature and distribution of laboratory specimens from six HBAg inpatients

\section{Discussion}

The hepatitis B antigen (HBAg) appears to be a specific marker for the viraemic phase of so-called 'serum' hepatitis (Blumberg et al, 1968; Prince, 1968 ), although there is no direct evidence that it is the infectious agent of the disease (Taylor, 1972). The significance of the corresponding antibody (HBAb) is less certain, but it probably represents evidence of earlier infection (Department of Health and Social Security, 1972a). Heathcote and Sherlock (1973) studied the spread of acute viral hepatitis type B, and found that non-parenteral spread was more common than parenteral. Close contact with HBAg carriers now appears to be the single most important factor in the spread of type B hepatitis in a large, urban, cosmopolitan community.

Reports of the prevalence of HBAg and HBAb among healthy blood donors have been summarized (Maycock, 1972). The prevalence of the antigen appears to be higher in paid than in unpaid donors and also to show considerable geographical variation, the lowest rates quoted being in the United Kingdom $(0.07 \%$ in Sheffield) and the highest in Kenya $(6.0 \%)$. Less information regarding the prevalence of the antibody is available; a rate of $0.03 \%$ in Sheffield can be compared with a rate of $0.4 \%$ in France.

Little information is available regarding the prevalence of HBAg in general hospital patients. Cossart has reviewed the prevalence of HBAg in various groups of patients at special risk (Cossart, 1972), and a prevalence rate of $0.34 \%$ for hospital admissions in Denmark has been reported (Cherubin 
and Prince, 1971). An overall prevalence rate of $1.34 \%$ for HBAg has recently been reported in patients attending a venereal disease clinic in London (Jeffries, James, Jefferiss, MacLeod, and Willcox, 1973). Fulford, Dane, Catterall, Woof, and Denning (1973) also found a high frequency of $\mathrm{HBAg}$ and of $\mathrm{HBAb}$ in patients attending a clinic for sexually transmitted diseases. In both these studies it was shown that there were distinct populations, the highest rates of exposure to type B hepatitis virus being found in homosexual patients. Heathcote and Sherlock (1973) have also emphasized the importance of close sexual contact in the transmission of type B hepatitis.

Many different methods of testing for HBAg and $\mathrm{HBAb}$ have been described, and these vary considerably in their sensitivity (Department of Health and Social Security, 1972b; Taylor, 1972). It is therefore quite possible that some of the differences in reported prevalence are due to variations in the sensitivity of methods of testing used. The World Health Organization Report (1973) states that the successful detection of HBAg and HBAb depends as much on the meticulous performance of the chosen test as on its relative sensitivity. For these reasons comparison and interpretation of reported prevalence in different studies require considerable caution. In the present study both hospital patients and blood donors were tested in one centre using the same technique (IEOP). Bloofield (1973) has challenged the validity of using blood donors in comparative studies, because in some countries potential donors with a history of jaundice or of contact in the past six months with a case of jaundice are rejected. Cossart (1972) also considers that the exclusion of volunteers with a past history of jaundice makes a population of blood donors unrepresentative of the community as a whole. The World Health Organization (1973), however, suggests that individuals with a history of overt hepatitis may not have a high incidence of HBAg, and evidence supporting this contention has recently appeared (Wallace, 1973).

Clearly, however, both hospital inpatients and blood donors form highly selected groups of the general population, and within these groups of patients and of donors there are subpopulations according to age, sex, race, and social class. The patients studied showed considerable 'surgical' bias and formed a further selected group within the general hospital population. It is interesting nevertheless that the prevalence of HBAg was found to be very similar in both the patients and donors $(0 \cdot 12 \%)$, whereas the prevalence of HBAb was considerably greater in the patients $(0.27 \%)$ than in the donors $(0 \cdot 10 \%)$. That this difference is due to the exclusion of some potential blood donors because of their previous medical history seems unlikely (Wallace, 1973).

Potential modes of infection were identified in just over half the HBAg or HBAb hospital patients. Conversely and perhaps more importantly no such episode was identified in nearly half of these patients. These findings not only confirm the importance of blood donations unscreened for $\mathrm{HBAg}$ and the parenteral route of infection, but also lend support to the suggestion of a natural circulation of the virus in the community (Cossart, 1972). In their study of the spread of acute type B hepatitis, Heathcote and Sherlock (1973) found no definite source of infection in 24 out of 67 patients.

Although the possibility of subclinical hepatitis cannot be absolutely excluded, it seems more likely that the HBAg-positive hospital patients were 'healthy carriers' of the virus, since biochemical liver function tests were all normal. Similarly liver function tests were also normal in the HBAbpositive patients, in whom this finding was probably evidence of earlier infection. Hospitals must constantly be treating unknown carriers of HBAg.

The risks of handling specimens of unfixed tissues, blood, and body fluids from 'high-risk' patients have been emphasized recently (Department of Health and Social Security, 1972c). None of the patients in this study subsequently found to be HBAg of $\mathrm{HBAb}$ positive was regarded as a "high-risk patient when admitted to hospital. However, one in $862(0.12 \%)$ specimens submitted for routine blood grouping was found to contain HBAg in retrospect; in addition specimens had been examined in other laboratories for routine diagnostic purposes before this information became available. This study again emphasizes the importance of regarding all specimens as highly infective and of handling all specimens with great care.

\section{Refercnces}

Bloofield, T. H. (1973). Australia antigen in V.D. clinic patients Brit. med. J., 2, 779 .

Blumberg, B. S., Sutnick, A. I., and London, W. T. (1968). Hepatitis and leukemia: their relation to Australia antigen. Bull. N.Y. Acad. Med., 44, 1566-1586.

Cherubin, C. E., and Prince, A. M. (1971). Serum hepatitis specific antigen ( $\mathrm{SH})$ in commercial and volunteer sources of blood. Transfusion, 11, 25-27.

Cossart, Y. E. (1972). Epidemiology of serum hepatitis. Brit. med. Bull., 28, 156-162.

Department of Health and Social Security (1972a). Rosenheim Report: Hepatitis and the Treatment of Chronic Renal Failure, pp. 10-11. Dept. of Health and Social Security, London.

Department of Health and Social Security (1972b). Maycock Report: Revised Report of the Advisory Group on Testing for the Presence of Australia (Hepatitis-Associated) Antigen and its Antibody, pp. 4-5, 10. Dept. of Health and Social Security, London.

Department of Health and Social Security (1972c). Heggie Report: Safety in Pathology Laboratories, pp. 17-18, 53. Dept. of Health and Social Security, London. 
Fulford, K. W. M., Dane, D. S., Catterall, R. D., Woof, R., and Denning, J. V. (1973). Australia antigen and its antibody among patients attending a clinic for sexually transmitted diseases. Lancet, 1, 1470-1473.

Heathcote, J., and Sherlock, S. (1973). Spread of acute type-B hepatitis in London. Lancet, 1, 1468-1470.

Jeffries, D. J., James, W. H., Jefferiss, F. J. G., MacLeod, K. G., and Willcox, R. R. (1973). Australia (hepatitis-associated) antigen in patients attending a venereal disease clinic. Brit. med. J., 2, 455-456.

Maycock, W. d'A. (1972). Hepatitis in transfusion services. Brit. med. Bull., 28, 163-169.
Prince, A. M. (1968). An antigen detected in the blood during the incubation period of serum hepatitis. Proc. nat. Acad. Sci. (Wash.), 60, 814-821.

Taylor, P. E. (1972). Laboratory tests for Australia (hepatitisassociated) antigen and antibody. Brit. med. Bull., 28, 138-141.

Wallace, J. (1973). Hepatitis B antigen in V.D. clinic patients. Brit. med. J., 3, 347 .

Wallace, J., Milne, G. R., and Barr. A. (1972). Total screening of blood donations for Australia (hepatitis-associated) antigen and its antibody. Brit. med. J., 1, 663-664.

World Health Organization (1973). Viral Hepatitis (Technical Report Series, No. 512), pp. 9 and 22. HMSO, London. 